\title{
DEMOCRACIA COSMOPOLITA VERSUS POLÍTICA INTERNACIONAL
}

\author{
Rafael Duarte Villa \\ Ana Paula Baltasar Tostes
}

Desde a publicação da Paz Perpétua de Kant, em 1795, um tema recorrente tem sido o da democratização do sistema internacional. Mas o que isso significa realmente? É possível deduzir o funcionamento do sistema de Estados de princípios e práticas próprias das democracias nos Estados nacionais? Face ao fenômeno da globalização, colocam-se outras questões: qual é o locus territorial apropriado para a idéia de democracia como prática transnacional? Nos últimos 20 anos houve uma forte retomada dos enfoques que discutem as relações entre democracia e sistema internacional. Em uma primeira linha de argumentações podemos destacar os neo-idealistas, que têm retomado as teses da paz democrática em bases históricas contemporâneas - Michael Doyle (2000) tem-se transformado numa referência importante nessa linha de pesquisa. Uma segunda proposição, que oscila entre uma visão normativa e o comprometimento com um projeto de hegemonia global estadunidense, tem declarado o fim das ideologias, tendo a globalização da idéia democrática como ponto final das doutrinas políticas (Fukuyama, 1989). Finalmente, uma terceira linha de argumentações tem enfatizado as bases transnacionais da democracia nos 
efeitos da globalização e na institucionalização de um sistema democrático global de governança. Dahl (1994), Held (1998) e Falk (1995), entre outros, podem ser relacionados como autores que têm discutido esses três temas. E é nesse terceiro grupo que focamos a análise neste artigo. O objetivo é mostrar e tensionar os desconfortos, hipóteses fortes e teses otimistas e/ou pessimistas que perpassam os vínculos entre o modelo westphaliano internacional de soberania, a democratização do sistema internacional e a sociedade civil internacional. Dividimos o artigo em cinco partes: na primeira recuperamos a discussão clássica sobre democracia e relações internacionais; na segunda tratamos das relações entre globalização e democracia; na terceira, as tensões entre democracia (transnacional) e as novas noções de representação; na quarta aprofundamos as tensões entre democracia e territorialidade estatal e, na última, mostramos os pontos críticos da visão celebratória da socie-

70 dade civil internacional pregada pelas teorias cosmopolitas da democracia.

\section{Democracia e relações internacionais na visão clássica}

A visão do universalismo ou idealismo clássico kantiano fez da natureza política do regime republicano democrático um elemento fundamental ou condição para o estabelecimento de uma ordem de direito internacional ou de uma paz que fosse perpétua. Na Paz Perpétua (1795), Kant sustenta a famosa hipótese de que Estados republicanos convivem em paz uns com outros. A discussão sobre a ausência de conflitos bélicos entre Estados democráticos é o que no mundo acadêmico das relações internacionais passou a ser conhecido como paz democrática.

Uma pergunta que incita debates normativos reaparece sempre: estaria Kant correto ao afirmar que as democracias são fundamentalmente pacíficas? Segundo Cardin (1999, p. 2), a articulação da resposta a essa pergunta remete ao pró- 
prio debate teórico que envolve disputas axiomáticas entre o realismo e o idealismo. O enfoque realista, como é sabido, assume que certos atributos dos Estados são irrelevantes para uma eventual situação bilateral ou multilateral de paz e, para alguns, fatores sistêmicos constituem as melhores categorias interpretativas da realidade internacional. $\mathrm{O}$ realismo destaca que os elementos mais importantes da realidade internacional podem ser entendidos sem se levar em conta os diferentes regimes políticos internacionais, na medida em que, assim como a natureza humana é egoísta e imutável, os Estados jamais deixarão de ser expansionistas. Este pressuposto a respeito da natureza auto-interessada dos homens e das instituições, e ainda da irreversibilidade do conflito como fruto da coexistência entre atores, não deixa brechas para a defesa da relação necessária entre regime político e paz.

Diferentemente, defensores da perspectiva idealista de inspiração kantiana advogam que a história tem demonstrado de maneira convincente a inexistência de guerras entre democracias no século XX. Uma nova literatura sobre a paz democrática também apresenta duas vertentes: a primeira defende que os Estados democráticos são pacíficos tanto com Estados democráticos quanto com Estados não-democráticos e, de acordo com a segunda vertente, só pode haver paz perpétua entre Estados democráticos. Huth \& Allee (2002, p. 4-5) batizaram essas duas escolas de pensamento, respectivamente, de Monadic version of the democratic peace (versão monádica da paz democrática) e Dyadic version of the democratic peace (versão diádica da paz democrática).

Para tentar corroborar ou refutar tanto uma versão quanto a outra, novos esforços de compreensão dessa velha discussão foram realizados tanto no plano teórico quanto no plano empírico embora, em ambos os casos, não se tenha atingido nenhuma conclusão consensual na literatura. No plano teórico, a premissa de que as democracias seriam mais pacíficas passou a ser especificada, para além 
da interdependência econômica e da confiança mútua, a partir das normas e mecanismos políticos compartilhados, que facilitariam a resolução de conflitos e restringiriam os enfrentamentos armados. Em uma abordagem localizada dessa paz democrática assentada em normas e procedimentos, encontramos um conceito de comunidade pluralista de segurança (pluralistic security community), que seria constituída quando, em um certo território, seus habitantes atinjam um sentimento de comunidade, posse de instituições e práticas fortes e disseminadas suficientemente para assegurar expectativas de mudanças pacíficas no seio de sua população. Nesse sentido, Canadá e Estados Unidos constituiriam uma comunidade de segurança pluralística, assim como os membros da União Européia (Dominguez,1998, p. 12).

Esse aspecto de normas comuns compartilhadas incita, então, a pergunta que buscamos enfocar: seriam as democracias predispostas à paz, devido ao seu sistema de 72 governo ou devido às suas identidades similares? Se os países projetam em sua política externa a sua identidade nacional, países com regimes políticos, sistemas econômicos, culturas e experiências históricas semelhantes, deverão se pautar em valores afins derivados de suas auto-imagens. Assim, auto-imagens convergentes mitigam os conflitos entre os países, enquanto identidades divergentes os estimulam, não sendo a ausência de conflito exclusiva de democracias.

Da mesma maneira, democracias podem não ser tão homogêneas a ponto de, no longo prazo, se tornarem mais propensas a conflitos de acordo com o grau de distanciamento de seus regimes políticos e de suas sociedades. Essa questão seria tanto mais premente conforme a expansão de democracias por países com culturas diversas da ocidental, em que se amplie a variedade de instituições e práticas democráticas de tal maneira que terminem por se afastar de seu modelo original liberal. 
Historicamente, entretanto, sabemos que, desde Tucídides, em sua obra clássica História da Guerra do Peloponeso, o estudo das relações internacionais lida com a permanente ameaça de guerra entre suas unidades, no caso, entre as cidades-estado gregas. Também desde esse livro há a presença, na teoria das relações internacionais, da idéia da democracia - um demos que governa diretamente, algo ocorrido em Atenas cerca de 5 séculos antes de Cristo. Nesse sentido, Doyle acredita que Tucídides narra uma grande tragédia democrática, pois a guerra do Peloponeso se desenvolve com o enfraquecimento progressivo de Atenas (Doyle, 2000, p. 23-24). Enquanto Tucídides inaugura a tradição realista das relações internacionais (sem o saber, naturalmente), é no âmbito do liberalismo moderno que a democracia voltará a ocupar um lugar de destaque. Democracia e Estado passam a buscar uma solução comum para sua coexistência na busca de organizações políticas que modelem um mundo moderno. Naturalmente, o liberalismo clássico aparece como sendo mais adequado à esfera doméstica, por se apoiar na defesa de direitos individuais, da propriedade privada e em um sistema de governo representativo.

Nos séculos XIX e XX, porém, os liberalismos de Bentham e de Wilson buscariam uma aplicabilidade das idéias liberais ao problema do convívio internacional. Esses autores acrescentaram assim um outro elemento importante ao universalismo democrático kantiano: o poder da opinião pública sobre os assuntos internacionais para assuntos fundamentais de interesse, tais como, desarmamento dos Estados, diplomacia aberta e implementação dos tratados. A teoria da harmonia dos interesses estava baseada nos pressupostos do iluminismo, que previa uma razão capaz de revelar a verdade e o bem. Segundo E. Carr (2001), a crença do século XIX na opinião pública compreendia dois pontos: o primeiro que a opinião pública está fadada, no longo prazo, a prevalecer. No segundo, que a opinião públi- 
ca estaria sempre certa (Bentham). Acrescentava-se a isso a idéia de que um espírito cultivado na educação de seus sentidos e de suas paixões seria capaz de discernir entre o certo e o errado. Prescrevia-se que os governantes tentariam utilizar os melhores e mais justos dos critérios diplomáticos para não se expor ao julgamento da opinião pública. No entanto, para um realista como Carr, o expansionismo sem limites da década de 30 e o fim da Liga das Nações mostrariam claramente a punição dessa utopia.

Os realistas elitistas contemporâneos acreditam que o padrão ideal de relações internacionais é aquele no qual apenas um grupo especializado teria acesso às decisões políticas, pois se deve evitar a influência da opinião pública por estar sempre submetida a paixões e manipulações, além da pressão de interesses setoriais (Fonseca, 1998, p. 111). Essa postura se vê refletida também na passagem de Tocqueville que sugere que a dificuldade das democracias está em buscar 74 realizações de objetivos permanentes e levar adiante sua execução. Assim, além dos assuntos de guerra e paz, a democracia como forma de governo também estaria ligada à questão da eficiência na condução da política externa. Por essa razão, para Tocqueville, a democracia é considerada incompatível com a participação prudente na política internacional, como se pode conferir em suas palavras:

“A política exterior não exige o uso de quase nenhuma das qualidades que são convenientes à democracia, e pelo contrário determina o desenvolvimento de todos aqueles que lhe faltam. A democracia favorece o crescimento dos recursos interiores do Estado; propaga o conforto, desenvolve o espírito público; fortifica o respeito pela lei nas diferentes classes da sociedade, coisas que só têm influência indireta sobre a posição de um povo perante o outro. Mas a democracia só dificilmente poderia coordenar os detalhes de uma grande empresa, deter-se num propósito 
e depois segui-lo obstinadamente através dos obstáculos. É pouco capaz de combinar medidas em segredo e de esperar pacientemente os seus resultados. São essas qualidades que pertencem mais particularmente a um homem ou a uma aristocracia. Ora, são precisamente essas qualidades que, afinal, vêm a fazer com que um povo, como indivíduo, acabe por dominar." (Tocqueville, 1998, p.177)

No âmbito doméstico, esse debate remonta mais uma vez à sabedoria ou ignorância das massas, estas que seriam governadas pela razão e pela prudência como pensam os iluministas, ou pela manipulação, força e interesse - logo, propensas a enganos e à guerra. As massas seriam lentas para as tomadas de decisão, pela seqüência de procedimentos necessários, principalmente na reação a ameaças externas. Além disso, as massas seriam também instáveis ou passíveis de manipulação, segundo alguns realistas. Nincic (1992) discorda dessas críticas realistas à democracia no sentido de que elas pressupõem que o debate democrático restringiria a eficácia da política externa, porque os cidadãos e políticos não saberiam como defender o interesse nacional, quando, na verdade, o que aconteceria é que os processos democráticos redefiniriam o interesse nacional e ampliariam seus objetivos para além da mera sobrevivência.

Outra preocupação referente às democracias seria que a incapacidade de falar com uma só voz prejudicaria as negociações internacionais. Entretanto, o trabalho seminal de Putnam (1993), em que é aplicada a teoria da barganha às negociações internacionais, demonstra que a pressão interna das democracias, longe de ser um sinal de fraqueza, pode ser uma fonte de poder ao sinalizar aos negociadores do outro país que não serão aceitas concessões. Caso os líderes do país democrático ou do outro país com o qual esse negocia não levem em consideração a opinião pública, o acordo simplesmente não se sustentará. 
Finalmente, outra contenda da paz democrática diz respeito à relação entre o público interno das democracias e a responsabilidade institucional (institutional accountability) ${ }^{1}$. Se os cidadãos de uma democracia fossem realmente menos inclinados a arcar com os custos materiais das guerras e mais avessos a qualquer perturbação quanto aos seus negócios privados, não veríamos, tantas vezes, os próprios cidadãos e eleitores clamarem pela guerra. A vigilância da diplomacia por parte dos cidadãos e o fim dos acordos secretos não foram eficientes antídotos contra a belicosidade dos governantes, como acreditavam Kant e Woodrow Wilson. Por exemplo, em 1993, Chile e Peru assinaram a Convenção de Lima para solucionar todas suas disputas fronteiriças, porém a exploração do acordo pela oposição forçou o presidente peruano Alberto Fujimori a retirar o tratado de votação por medo de ser derrotado em sua campanha pela reeleição (Dominguez, 1998).

76 Essa sensibilidade do público doméstico a concessões territoriais parece ser tão importante quanto à suposta relutância das democracias ao uso da força, sendo ambos os fatores que constituem "os custos de audiência" (audience costs) a serem considerados pelos líderes em países democráticos (Huth, 2002, p. 12-13). Por causa disso, alguns especialistas, como Dominguez, acreditam que as democracias exibem uma tendência ao status quo, dificultando tanto a escalada de conflitos armados, como a assinatura de acordos de paz e de consolidação de fronteiras (Dominguez, 1998, p. 24).

Ao contrário da perspectiva realista, Bobbio é otimista e defende a necessidade da democratização do sistema internacional. Sua hipótese é que a democratização do sistema internacional é também um problema do Estado nacional. Isto porque, se as democracias são mais pacíficas, a paz inter-

1. Cf. Huth (2002), p. 8-9. 
nacional dependeria da extensão progressiva dos Estados democráticos. Ou seja, o crescimento dos Estados democráticos levaria o sistema internacional a ser mais democrático. Entretanto, na realidade política contemporânea, é difícil estabelecer uma relação causal entre regimes domésticos democráticos e sistema internacional. Tomemos, por exemplo, condutas políticas que são "incoerentes" com os princípios que inspiram seus sistemas políticos internos: EUA apoiando ditaduras na América Latina, Ásia ou África, ao mesmo tempo em que construíam democracias na Europa e o Japão; ou a URSS apoiando o movimento de descolonização, ao mesmo tempo em que esmagava movimentos políticos nos seus estados satélites. Por esse descompasso exemplificado historicamente, os realistas sugerem, apropriadamente, que não existe uma necessária correspondência entre a natureza de um sistema político doméstico e sua agenda de política externa - pois esta seria sempre expansionista e estratégica. De outra forma, há uma diferença clara entre política doméstica e política externa que se sustenta no pressuposto do egoísmo dos atores que coexistem no ambiente anárquico internacional.

\section{Globalização versus democracia}

Outra visão sobre a democratização do sistema internacional parte de uma reflexão normativa sobre a interação e integração de três fatores: sistemas políticos nacionais democráticos, globalização e governança internacional. De acordo com essa versão de Held $(1991 ; 1996)$, as teorias das democracias deveriam levar em conta também falhas que a democracia liberal não foi capaz de processar: as condições para a possibilidade de uma participação política, as formas de controle democrático e o escopo democrático do decision-making. No entanto, existe outro lado da democracia liberal que requer especificações mais detalhadas. O problema da democracia além das fronteiras e o impacto que esse 
problema tem sobre os conceitos nucleares da democracia como legitimidade e consenso.

O primeiro problema apontado por Held (1996) é a defasagem ou incongruência entre as decisões nacionais e suas conseqüências extranacionais. A teoria liberal da democracia assume uma simetria e congruência entre decision-making político e os cidadãos-eleitores. E este é um processo que visa funcionar em bases nacionais - porém o fenômeno da regionalização e da globalização e seus níveis de interdependência contestam questões-chave da teoria da democracia contemporânea. A comunidade nacional não toma decisões que afetam unicamente essa comunidade e governos não tomam decisões que afetam só a seus próprios cidadãos. Além disso, sabemos que o fenômeno da regionalização e da globalização e seus níveis de interdependência desmontam a teoria da congruência.

A inadequação da idéia de congruência se visualiza 78 melhor quando vamos ao coração de outro argumento da teoria democrática: a idéia de que o consentimento legitima os governos e o sistema estatal. Isto é, o mecanismo pelo qual os indivíduos expressam suas preferências políticas e os cidadãos, como um todo, conferem autoridade aos governantes para habilitar direito e regular a vida econômica e social. Segundo, o princípio da regra da maioria, ou o princípio de que as decisões tomadas pelo número maior de votos é a raiz da decisão política legítima. Porém, a idéia do consentimento através das eleições e a idéia de que os constituintes relevantes de um acordo voluntário são as comunidades de um território passa a ser problemática quando consideramos os níveis de interconexão regional e global. Assim, a idéia de "comunidade relevante" é amplamente contestada. Que consentimento é necessário em decisões concernentes à AIDS, chuva ácida, entre outros? A quem deveriam ser prestadas as contas? As implicações disto são desconsideradas não somente pelas categorias de 
consentimento e legitimidade, mas também por qualquer teoria da democracia sobre a natureza do constituinte, o significado de representação, a forma e escopo da participação e a relevância do Estado-nação.

Em relação à globalização, Held (1995) observa um paradoxo: da África à América Latina, mais e mais nações reivindicam a idéia do "governo do povo", exatamente numa época em que os níveis de interconexão ou interdependência o questionam. Isso leva a pensar numa nova agenda para a democracia. Diferentemente de teses como a de Kant, que compreende que o regime político nacional levaria a uma estabilização do sistema internacional ou de Bobbio, segundo Held (1995), o que existe de novo é que a teoria democrática teria que dar conta da mudança de significado da democracia dentro da ordem global e do impacto da ordem global no desenvolvimento das associações democráticas.

A verificação do contexto da globalização, do seu processo de intensificação e de suas conseqüências para o exercício de uma democracia no sistema internacional pressupõe uma compreensão mais ampla das conseqüências do aparecimento de atores não estatais e da proliferação da atuação de agentes sociais no âmbito transnacional. Novas instituições, naturalmente, pressupõem novas fórmulas de participação e de democracia que ainda não estão resolvidas.

Durante a maior parte do século passado, intelectuais de diferentes procedências e diversas orientações ideológicas desejaram, previram ou trabalharam pela dissolução do Estado (Strange, 1992). Todavia, o Estado permanece, ainda que modificado. Ao mesmo tempo em que é foco de pressões do mercado internacional, da "financeirização" da economia, da globalização no setor da comunicação e do crescimento dos atores não estatais no cenário internacional, o Estado parece tentar se fortalecer e se manter como unidade institucional ainda indispensável, mesmo redimen- 
sionado no seu papel e nas formas de exercitar e de legitimar a sua autoridade. É por causa disso que, em diversas áreas de pesquisa (ciências sociais, política, economia, direito etc.), o interesse atualmente se volta para as mudanças do Estado, em particular para as instituições através das quais um "novo Estado" pode ganhar legitimidade e eficiência. Segundo a perspectiva internacionalista de Hedley Bull (2002), por exemplo, assim como os Estados sempre foram atores privilegiados nas relações internacionais, não é possível imaginar que estes deixariam de ser. Entretanto, se é preciso rever o papel dos Estados e as condições e limites de suas instituições, é preciso ainda rever o alcance da ação das sociedades civis e a eficiência das regras do jogo democrático diante das novidades políticas trazidas pelo processo de intensificação da interconexão entre os povos, os Estados e os mercados.

Desde o fim do século XX, em especial, foram-se desen80 volvendo, alternando e acumulando vários tipos novos de atores, forças de influência e de coerção no convívio internacional, tais como: forças religiosas, o mercado mundial, o capital internacional, as atividades industriais territorialmente dispersas, as organizações internacionais, os blocos econômicos, ONGs, enfim, instituições internacionais em geral que, muitas vezes, estabelecem limitações adicionais às opções práticas disponíveis à soberania dos Estados (Joseph \& Falk, 1992, p. 252-253). Charles Tilly (1996, p. 48) inclui nesses casos, destacando certa continuidade histórica, a existência de organizações ou redes mundiais de negociantes de mercadorias caras e ilegais, como drogas e armas - forças marginais de influência que variam com a história, mas que, de fato, sempre existiram. O que disto se conclui, em primeiro lugar, é que os Estados dificilmente poderiam ser os únicos atores a ditar regras de convívio ou princípios valorativos na sociedade internacional, mas o sistema contemporâneo ainda está baseado em formalismos institucionais e jurídicos 
que deixam um espaço intocável para o poder dos Estados soberanos.

A década de 80 foi marcada por um otimismo a respeito do fenômeno do "esgarçamento das fronteiras" (de comunicação, de bens, de capital, de poder), como se isso pudesse contribuir para uma aproximação dos povos de modo majoritariamente positivo. Entretanto, vimos presenciando que as condições contemporâneas de interdependência e globalização não trouxeram necessariamente uma agregação pacífica ou uma integração solidária entre as culturas e os diversos sistemas econômicos. Houve até mesmo um desenvolvimento paralelo de fatores de exclusão, de desagregação em alguns setores e ainda novos modos de dominação. A ordem e a desordem se alternam nos comportamentos dos atores internacionais num contexto de reordenação do sistema mundial. Novos movimentos antidemocráticos surgem, reaparecem os antigos xenofobismos, guerras nacionalistas e religiosas etc. - mas, em meio a tudo isso, vêem-se os países ricos do Ocidente baseando suas decisões políticas em razões econômicas.

Esse aumento da interdependência, interconexões e influências recíprocas no âmbito da convivência internacional extrapolou o setor da economia, principalmente na última década, com a aceleração e facilitação do acesso às tecnologias de comunicação, atingindo assim amplos setores da vida social - o que tem sido chamado de "intensificação da globalização”. Com esta última expressão, o que se pretende enfatizar é a aceitação da idéia de que a sociedade dos Estados sempre foi globalizada em algum grau. Segundo Paul Singer, apesar de ter sofrido algumas interrupções e retrocessos ocasionais, nada fez com que "a internacionalização" sumisse por um longo período, pois desde os "dois séculos anteriores às grandes navegações, os laços comerciais entre os grandes impérios do continente asiático e a periferia européia não fizeram mais que se intensificar [...]" (Singer, 1997, p. 39.) Ou seja, as grandes navegações 
surgiram com as novas tecnologias navais, mas, sem elas, a interconexão entre os Estados já existia.

Nesse contexto global surgem várias crises e desconfortos na utilização de certas definições do Estado e de seus atributos. Um dos grandes conceitos da política que fica em questão é o da soberania. O que acontece com a supremacia dos Estados nessa conjuntura de interconexões políticas, econômicas e sociais? E o que pode ocorrer com a supremacia da vontade popular diante do estreitamento de relações intergovernamentais e formação de organizações supranacionais baseadas em razões puramente econômicas de desenvolvimento e competição?

Diante de uma riquíssima literatura que visa tratar do tema da "crise da soberania" ou "crise do Estado", encontramos numa reflexão feita por Charles Beitz (1991) um percurso satisfatoriamente seguro para sistematizar os argumentos a respeito das mudanças que de fato ocorreram no alcance 82 do poder dos Estados e das relações entre eles. Em resumo, Beitz trata de alguns dos principais novos temas que povoam a literatura sobre as novas características das relações internacionais contemporâneas. $\mathrm{O}$ autor afirma que é a partir do exercício externo da soberania dos Estados contemporâneos que surgem suas novas dimensões problemáticas: o problema teórico (ou normativo), o problema político (ou institucional) e o problema legal (ou jurídico). Segundo Beitz, refletir sobre "a crise da soberania” implica refletir sobre essas três dimensões críticas, que se referem respectivamente aos problemas do conceito de soberania, da crise do Estado-nação (que é a organização institucional soberana privilegiada) e da crise dos mecanismos coercitivos modernos internacionais - que, por serem prioritariamente pacíficos, envolvem o direito internacional. Estes três problemas estão implicados na soberania, de modo que é preciso reconhecer que há múltiplas faces da crise do estabelecimento e da organização do poder político diante das transformações mundiais. 


\section{A democracia (transnacional) e a representação}

Em ensaio publicado em 1994, Robert Dahl dedica-se aos novos aspectos da democracia contemporânea e descreve um novo dilema que se refere aos problemas da democracia transnacional. Segundo Dahl, as grandes transformações históricas da democracia estão sempre relacionadas a uma "mudança em escala". As dimensões e o alcance do poder da polity são os principais fatores transformadores dos Estados e, no caso da União Européia, os problemas do seu "déficit democrático" ${ }^{2}$ refletem o novo dilema democrático ${ }^{3}$ : “[...] a capacidade de os cidadãos exercerem controle democrático sobre as decisões do governo versus a capacidade de o sistema responder satisfatoriamente às preferências coletivas de seus cidadãos" (idem, p. 28) ${ }^{4}$.

Na mesma linha de David Held, Dahl considera o problema do alargamento das fronteiras políticas como um fenômeno que implica mudanças substantivas na reflexão sobre as novas condições e restrições da realização da democracia contemporânea, já que se espera uma maior capacidade de adaptação da democracia nacional (esfera estatal) à democracia transnacional (arena extra-estatal ou interestatal).

"As fronteiras de um país, mesmo as de um país tão grande
como os Estados Unidos, tornaram-se menores que os

2. Expressão popularizada pela mídia e pela literatura que faz referência aos problemas democráticos da União Européia, que ficaram mais evidentes desde o Tratado de Maastricht (tratado acordado entre 1991 e 1992, que decidiu as metas da União política da Comunidade Européia que entraram em vigor em novembro de 1993).

3. Na primeira consulta popular na Dinamarca, quanto à ratificação do Tratado de Maastricht, o resultado foi negativo, e só após algumas modificações impostas pela Dinamarca para a sua adesão à Comunidade Européia é que, com nova consulta, a população aprovou a incorporação do tratado. Dahl destaca a importância desta reação do povo dinamarquês.

4. "[...] the ability of the citizens to exercise democratic control over the decisions of the polity versus the capacity of the system to respond satisfactorily to the collective preferences of its citizens." 
limites das decisões que afetam significantemente os interesses fundamentais de seus cidadãos. A vida econômica, o meio-ambiente, a segurança nacional e a sobrevivência de um país são altamente e provavelmente cada vez mais dependentes de atores e ações que estão fora das fronteiras de um país, e não diretamente sujeitos ao seu governo" (Dahl, 1994, p. 26) ${ }^{5}$.

Na verdade, Dahl distingue três momentos que funcionam como marcos históricos para se compreender as grandes transformações da democracia política - que colaboram para a reflexão sobre as dificuldades em conceber-se a UE como uma ordem democrática. O primeiro deles é o próprio aparecimento do sistema democrático, ocorrido na primeira metade do século V a.C. na Grécia, quando cidades-estados não democráticas (tipicamente aristocráticas, oligárquicas, monárquicas ou mistas) se transformam em 84 democracias diretas.

A segunda transformação da democracia como um sistema se deu a partir do surgimento dos Estados nacionais, que passaram a exigir uma democracia em grandes dimensões, em comparação às cidades-estados gregas, que eram pequenas organizações políticas. $\mathrm{O}$ significativo aumento das dimensões da democracia, que se dá com o surgimento das democracias nacionais, passa a exigir a representação. A democracia (ou o governo do povo) deixa, então, de ser direta, passando a ganhar características diferenciadas, tornando-se representativa.

\footnotetext{
5. "The boundaries of a country, even one as large as the United States, have become much smaller than the boundaries of the decisions that significantly affect the fundamental interests of its citizens. A country's economic life, physical environment, national security, and survival are highly and probably increasingly dependent on actors and actions that are outside the country's boundaries and not directly subject to its government."
} 
Atualmente, sabe-se o quanto a democracia representativa tem um "custo de governabilidade" e isto já está previsto e aceito no seio das sociedades nacionais como conseqüência natural da descentralização do poder e da sua "sobrecarga”. Ou seja, há sempre uma discrepância entre a capacidade dos cidadãos e instituições civis de demandar ação dos poderes públicos e a capacidade de resposta ou ação eficaz do Estado democrático representativo (Bobbio, 1988). Por tudo isso, faz parte dos procedimentos democráticos uma certa demora na resposta, resultante da complexidade dos recursos que visam a uma satisfação consensual (que, em última instância, deve estar respaldada sempre no devido processo legal). Em um contexto democrático contemporâneo, valores como o procedimento e as formas institucionais que dão ao cidadão comum acesso ao poder político instituído são fundamentais para a realização de um Estado democrático. Esse poder se traduz numa bateria de direitos democráticos, como o direito de demandar e de esperar resposta do Estado sobre qualquer conflito de direitos, o direito à decisão justa (porque baseada no processo legítimo de pedido e resposta da prestação jurisdicional do Estado), o direito à participação na constituição das instituições representativas etc.

Segundo Dahl (1994), atualmente, estamos vivendo a era da terceira grande transformação das dimensões democráticas: a era da transnacionalidade da política. Diante do aumento das dimensões territoriais pode-se "perder democracia”, ou melhor, desde a democracia direta grega, foram-se perdendo as melhores condições de realização da democracia devido às necessárias adaptações às proporções gigantescas do governo e das dificuldades no controle do poder. Todo o processo burocrático, que torna morosa a resposta do Estado representativo democrático, visa garantir a legitimidade da ação política, assim como algum possível controle das instituições que se colocam como intermediárias entre os cidadãos e o governo. Um mundo globali- 
zado pressupõe que a participação e o controle democráticos tornem-se cada vez mais difíceis, distantes, ineficientes, inacessíveis - devido ainda a múltiplas influências e vias de coercitividade. Por isso é preciso se repensar os mecanismos de participação na democracia contemporânea - não mais direta, não mais nacional representativa, mas transnacional. Ou seja, na medida em que o poder político é profundamente interconectado em redes complexas de influências de forças, citando David Held, Dahl endossa a necessidade de reafirmação do problema da representação que também deve acessar essas redes transnacionais de participação e controle. Nesse contexto, surge a necessidade de reconstrução institucional dos espaços democráticos. A democracia de dimensões transnacionais requer um novo aparato institucional que deve ser diferente, em muitos aspectos, e talvez radicalmente diferente, das "instituições políticas familiares à democracia representativa” (Dahl, 1994, p. 27).

86 Essa terceira grande transformação da democracia vem ocorrendo desde que "os atores" tradicionais do sistema internacional, os Estados, foram perdendo condições de controle de sua autonomia política, econômica, social e cultural. A realidade globalizada exigiu dos Estados ações coordenadas, associação e integração com novos "atores" e forças que surgiram no âmbito das relações internacionais: o capital internacional, as atividades industriais dispersas territorialmente, as organizações internacionais, blocos econômicos, ONGs e instituições internacionais em geral, que estabelecem limitações adicionais às opções práticas disponíveis à soberania dos Estados (Joseph e Falk, 1992, p. 252-253).

O fato é que tais transformações no mundo das relações políticas implicam mudanças, por exemplo, na concepção de participação dos cidadãos. Segundo Dahl, pode-se comparar tal "perda" ou "erosão" do controle da polity pelos cidadãos da democracia transnacional atual com o que se deu na passagem da democracia direta para a representa- 
tiva. No contexto da globalização, os Estados não são mais independentes para definir suas estratégias políticas e, além disso, os cidadãos perderam o controle sobre algumas ações políticas que definem o rumo dos Estados. Decisões importantes são tomadas, muitas vezes, fora do âmbito estatal e isto traz conseqüências para a democracia e para a representação. Os mecanismos de controle dos cidadãos sobre os seus representantes nos processos constitucionais eram, até então, considerados razoavelmente satisfatórios; entretanto, a globalização tem produzido novas estratégias de associação política em moldes sofisticados de institucionalização, além do surgimento de blocos econômicos em geral e o caso atípico da integração européia.

\section{A democracia, a territorialidade e a soberania}

Atores políticos e religiosos, forças de influências variadas e outros mecanismos de dominação externa sempre afetaram o exercício da autoridade dos Estados, guardadas as diferenças quanto às dimensões e aos meios. As saídas dos modelos absolutistas, primeiro na Inglaterra (com a revolução gloriosa, de 1688) e um século depois na França (com a revolução de 1789), são sempre marcadas pela invenção de instituições democráticas e pela divisão de funções da soberania. Mas é importante destacar que a noção de um exercício absoluto do poder só é abandonada na instância do exercício interno do poder político, ou seja, nas relações domésticas, territoriais ou nacionais; enfim, naquela esfera de autoridade que se pretende exercer sobre uma sociedade de homens. Entretanto, paralela às "sociedades nacionais" aparece a defesa da idéia de uma "sociedade internacional”, ou seja, um conjunto de Estados (cujos governos são reconhecidos como sendo legítimos e soberanos) que pretendem conviver como uma sociedade que escolhe a paz no lugar da guerra de todos contra todos. Os tratados de Westphalia do século XVII apareceram no momento em 
que os Estados começaram a se reconhecer reciprocamente como igualmente soberanos, interna e externamente ${ }^{6}$.

Essa foi a principal base da construção do que passa a ser chamado de ordem de Westphalia, ou seja, uma ordem pacífica em que a regra é o respeito mútuo à igualdade soberana. A igualdade jurídica no seio da sociedade internacional nada mais é do que uma réplica da igualdade formal das teorias liberais de Estado, ou seja, todos os indivíduos devem ter os mesmos direitos dentro de uma sociedade ${ }^{7}$. Uma espécie de democracia formal se pretende instituir a partir dessa regra de igualdade soberana, pois assim pequenas Repúblicas não são Estados menos soberanos do que um poderoso Reinado ou vice-versa. Buscou-se com isso preservar o respeito às fronteiras e à autonomia quanto ao modo de gestão das políticas nacionais, desde que sejam utilizados instrumentos coercitivos legitimamente reconhecidos como sendo democráticos.

Essa igualdade soberana propiciaria a necessária independência dos Estados, uns em relação aos outros, assim como a insubordinação a qualquer autoridade externa. Este é um princípio de ordem que busca mecanismos míni-

6. A distinção entre soberania externa e soberania interna, cara ao direito internacional, existe desde a Idade Média, pois o exercício interno do poder sempre se referiu a uma certa autonomia na livre regulação de interesses. Atualmente isto se revela pelo direito de auto-organização legislativa, administrativa e judiciária. Já a soberania externa sempre aparece como um "aspecto negativo" (Cunha, 1993, p. 61) da soberania, ou seja, significa a não sujeição do poder de outro Estado ou outra instância social qualquer, marcando com isso a independência daquele que for considerado assim soberano. Dentre os principais direitos do Estado, que se referem a sua soberania externa se destacam: o de ajustarem tratados ou convenções, o de legação ou representação diplomática, o de fazer a guerra e a paz, o de igualdade e respeito recíproco junto à sociedade internacional.

7. Na realidade, tal concepção de igualdade dos Estados foi introduzida no direito internacional por Vattel ("Le Droit des Gens", publicado primeiramente em 1758). Inspirado na noção de um estado de natureza em que os homens são iguais o autor concluiu que os Estados são também livres e iguais, no âmbito da convivência internacional. No Segundo Tratado do Governo Civil, de 1690, Locke já fazia considerações ao poder natural dos Estados no seio das suas relações externas. 
mos de democracia. Entretanto, sabemos que, assim como ocorre nos Estados de princípio liberal e democrático, a igualdade social não é garantida juridicamente em organizações que respeitam o princípio da liberdade individual. No ambiente internacional, então, o máximo que seria realista levar à discussão, seria a busca de correções sobre os espaços de participação e representação.

Se a ordem de Westphalia estabeleceu o triunfo da igualdade jurídica e soberana dos Estados, é porque se verificou que havia um interesse generalizado entre os países europeus pela paz naquele momento e que tal interesse era compatível com um modo de convívio internacional que estabelecia uma aparente anarquia na "sociedade de Estados”. Já que a nova regra era a da não sujeição a qualquer força ou poder externo, a exclusão dos atores externos e de seus poderes na condução das políticas nacionais foi considerada a principal característica do modelo de "ordem internacional" que se estabelecera. Entretanto, nem sempre o mundo das ações e dos comportamentos dos atores (nacionais e internacionais) manteve uma referência fiel às normas, aos ideais e aos princípios de conduta estabelecidos e aceitos. Apesar de a hegemonia quanto à razão jurídica dos Estados aparecer na modernidade como um grande plano estratégico de exercício do poder, e passar a fixar as formas modernas de coercitividade e de segurança, o fato é que os Estados soberanos democráticos continuaram a praticar violações e intervenções na política doméstica alheia.

Se a soberania precisa ser repensada num contexto de efetividade das forças globais de influência e de poder, é possível questionar se a ordem de Westphalia já foi altamente institucionalizada. Ou seja, antes que se discuta a crise do sistema de Estados e a crise do respeito à soberania internacional, é preciso verificar se as regras de convivência entre os Estados foram ininterruptamente respeitadas e se os 
princípios democráticos da política internacional são condizentes com os comportamentos de certos atores internacionais - como as grandes potências mundiais. A regra da não-intervenção, por exemplo, é a que mais sofre concessões e exceções. Leis de Estados mais poderosos têm justificado atos de violação de princípios da ordem de Westphalia invocando normas alternativas como ilegitimidade de regimes revolucionários ou segurança nacional, por exemplo. O que se vê no universo da política externa é uma proliferação de alegações de defesa da ordem justificando atos de interferência e intervenção na autonomia doméstica de países livres e soberanos. São múltiplas as exceções e de difícil justificativa. Ainda que essas se fundamentem na defesa de direitos universais como os direitos humanos, como é possível conferir poder de intervenção a Estados igualmente soberanos, uns sobre outros? ${ }^{8}$

Por tudo isso, são muitas as dimensões problemáticas 90 da soberania e é necessário sistematizar o tratamento do tema para que seja possível uma reflexão crítica sobre as mudanças provocadas pelas novas demandas políticas em um mundo globalizado. Segundo Beitz (1991), as dimensões críticas fundamentais do exercício da autoridade soberana, em primeiro lugar, se referem ao exercício externo do poder dos Estados. Em segundo lugar, podem-se agrupar os inúmeros debates sobre os problemas críticos da soberania em três grandes focos. Existe uma crise da soberania como conceito - o que é "ser soberano" atualmente? Existe uma crítica à soberania enquanto instituição, ou seja, no sentido de uma regra geral que deve inspirar a conduta dos Estados, implicando, por exemplo, o respeito à igualdade entre eles. E, finalmente, a soberania está em crise quanto aos seus aspectos jurídicos - já que a supremacia política moderna

8. Para saber mais sobre o tema, p. ex., Krasner, 1999. 
se revela, principalmente, pela não sujeição compulsória às regras extranacionais.

Segundo a perspectiva sociológico-histórica de Charles Tilly (1996), não obstante as transformações pelas quais tem passado o modelo de Estado moderno, desde sua origem, ele sempre resultou de lutas acirradas de poder, influência, coerção e cooptação de riquezas. Possivelmente, o que se vê ocorrer na política internacional atualmente não traz qualquer elemento novo sob a perspectiva dos interesses que se colocam em disputa, mas apenas novos instrumentos e novas retóricas políticas. Atualmente, é possível dizer que a busca dos interesses econômicos depende do rompimento de velhos atributos do poder do Estado, como a demarcação física e territorial da influência e do poder político, mas como fica a democracia? A característica da centralidade do exercício do poder político aparecia como conseqüência natural do exercício de uma autoridade soberana sobre um território determinado até a intensificação da globalização, mas, atualmente, um Estado tem capacidade de interagir em espaços transnacionais de modo mais intenso do que no passado, o que gera a dificuldade de se delimitar com precisão a fronteira política de um Estado. Se isto é um problema para a soberania, é um problema também para a democracia.

Significando, finalmente, uma continuidade ou uma grande transformação, o que é possível dizer, com certeza, sobre o fenômeno da "intensificação da globalização" é que ele tem sido apontado como causa da desestabilização de alguns fundamentos da ordem de Westphalia. Isto porque se transformaram algumas condições institucionais que asseguravam a correspondência entre a democracia liberal e o Estado-nação - uma delas é a relação do poder com o território sobre o qual ele é exercido.

Tomando-se como um primeiro fato relevante a geração de uma diminuição de distâncias propiciada pelas "novidades" da globalização, de fato, verificamos que as 
próprias relações sociais têm encontrado canais desvinculados dos espaços territoriais. A Internet propicia acesso a dados, informações e instituições; comunicação à distância, assim como a realização de negócios, conferências, trocas de experiências, idéias, influências etc.; enfim, traz a possibilidade de novas relações sociais e comerciais. Assim, não só os Estados, mas também indivíduos e instituições, subgrupos, microidentidades, idéias, culturas, tendências de comportamentos, têm ampliado o alcance do poder de influenciar e de ser influenciado - independentemente das redes políticas e sociais organizadas a partir dos Estados. Ademais, a perda da importância da territorialidade como processo privilegiado de demarcação de fronteiras e distâncias, logo delimitadora de espaços de atuação política, leva os Estados a buscarem novos padrões de agenciamento de forças, de ação política e da capacidade de organização de interesses e associações. Finalmente, toda essa tecnologia é incorporada 92 nas novas articulações econômicas e financeiras, propiciando uma atuação eficiente de setores da economia que não dependem da estrutura do Estado. Tudo isso parece apontar para uma crise da ordem de Westphalia.

Não é difícil concluir que os princípios da ordem de Westphalia têm sofrido concretas concessões e modificações no âmbito das relações internacionais ${ }^{9}$. Do mesmo modo, os

\footnotetext{
9. Segundo McGrew (1997), os princípios da ordem de Westphalia, tais como se têm desenvolvido nos últimos três séculos, são quatro: i) territorialidade, que é o princípio central da organização política moderna, já que sempre houve a necessidade da existência de fronteiras territoriais para a definição de limites de jurisdição legal e a conseqüente demarcação da extensão da autoridade coercitiva; ii) soberania, como sendo a última fonte de autoridade política e legal sobre o povo dentro de um território determinado e para fora dele; iii) autonomia, princípio que atribui, única e exclusivamente, ao Estado a capacidade de conduzir suas relações políticas internas e externas. Desse modo, só aos Estados compete a decisão sobre a concessão de poder ou a subjugação a uma autoridade externa; iv) e, por fim, a legalidade, que significa que as relações entre Estados soberanos podem estar sujeitas a leis internacionais, apenas na medida em que cada Estado consinta em ser compelido. Não podendo haver, portanto, autoridade legal acima do Estado que possa impor obrigações legais sobre ele ou sobre os cidadãos.
} 
princípios e práticas fundamentais à democracia liberal, como a representação e a cidadania (que estão associados a instituições do Estado-nação territorial soberano) têm encontrado exceções. Nesse contexto, tornaram-se problemáticas categorias como legitimidade, consenso e demais idéias básicas das teorias democráticas - como a ampla participação política, a identificação da natureza da base políticoterritorial do processo político (constituency), a necessidade da responsabilidade e do controle das decisões políticas (accountability) etc. (Held, 1991, 1996).

Os atuais pressupostos das teorias democráticas se universalizaram ao longo dos séculos XIX e XX, quando, no centro da teoria da democracia liberal, se postulou a relação "simétrica" e "congruente" entre os outputs (as medidas políticas ou decisões em geral) dos responsáveis pelas decisões políticas (os representantes) e os interesses dos que "recebem" essas decisões, ou seja, os cidadãos eleitores (Held, 1991). O procedimento escolhido e aceito para tal operação foi a "regra da maioria”, e foram sempre as fronteiras territoriais que determinaram a inclusão ou a exclusão dos cidadãos que participam das políticas representativas. A democracia moderna só se tornou conhecida sob a forma do Estado-nação e a partir da organização de princípios de poder e de responsabilidade delimitados por um território. Entretanto, autores como Held (1991) e Dahl (1994) despertam para o fato de que uma das conseqüências da transnacionalização da política é a necessidade de se reavaliar a própria idéia de "governo" como "consentimento voluntário de pessoas livres e iguais”, pois desde o surgimento do Estado representativo moderno o consentimento foi um princípio indiscutível do governo legítimo. Mas a interconexão dos Estados e da política faz surgir a dificuldade de se verificar, atualmente, a alegada legitimidade da ação política pela via do consentimento. Não apenas porque se perdeu uma delimitação precisa do espaço político 
privilegiado - de onde saem as decisões e para onde estas devem se voltar, mas principalmente porque há uma complexa rede de instituições que interagem no jogo político, impulsionados por interesses e cálculos racionais.

Assim, a perda da perspectiva da territorialidade está relacionada com o exercício legítimo da soberania dos Estados e com a democracia representativa. Segundo Held (1991; 1996), o remapeamento de ações entrecruzadas de poder não se enquadra na clássica distinção entre o exercício interno e externo da soberania do Estado. O autor acredita que a solução para a legitimidade democrática diante dessas novas demandas de poder está em criar novas ofertas de participação, novos espaços de exercício dos direitos civis, de modo que se faça uma interconexão também do controle democrático.

A solução para uma nova conceituação de fronteira dada por Kratochwill (1986) parece ser a forma mais efi94 ciente para se traçar atualmente trajetórias para o exercício do poder e da influência coercitiva de um Estado. Segundo o autor, mais importante para a soberania dos Estados, atualmente, não é o poder que se identifica sendo exercido nas suas fronteiras territoriais ou a partir delas, mas, sim nas suas "fronteiras funcionais". Assim, segundo o autor, continua a ser possível identificar-se uma fronteira política, desde que não levemos em conta aspectos meramente físicos ou concretos na análise do exercício do poder. É o alcance e a influência de um Estado nas suas relações internacionais que são determinantes, atualmente, da força e do poder de um Estado e da sua capacidade de crescimento e desenvolvimento. Conseqüentemente, é preciso se verificar as condições para a criação de mecanismos de participação e de identificação nos novos espaços de ação política. Isso nos remete a examinar o debate sobre as relações entre sociedade civil internacional e democracia. 


\section{Democracia, relações internacionais e sociedade civil}

$\mathrm{Na}$ outra ponta do debate, a problemática das relações entre democracia e relações internacionais tem-se concentrado nas tensões entre espaços deliberativos nacionais e transnacionais, o que implicaria pensar, não só na perspectiva normativa, a estruturação de uma sociedade civil internacional.

Os teóricos da democracia cosmopolita tem chamado a atenção para o fato de que os desdobramentos tecnológicos, econômicos e culturais da globalização redimensionam as funções do Estado, funções essas que se deslocam para outras instituições e minam a soberania estatal, mas de outro lado também geram políticas de solidariedade entre movimentos sociais e outros grupos de pressão como ONGs. Nessa direção é esclarecedor o conceito de "globalização desde baixo" de Richard Falk (1995), que associa a globalização com um refrescante ativismo transnacional que marca o nascimento da sociedade civil global. Os teóricos da democracia cosmopolita, como David Held (1996; 1998), preocupados com os impactos da globalização sobre as instituições democráticas liberais, têm defendido que a sociedade civil internacional (ou global) é um ponto de partida para se repensar a natureza da democracia liberal num mundo globalizado (1995; 1998). Os trabalhos de Held pretendem dar resposta a uma falha da democracia liberal: como pensar a democracia liberal em bases transnacionais? O projeto normativo do autor é o desenvolvimento de um conceito de "democracia cosmopolita", que encontraria sustentação histórica em arranjos institucionais, tais como a Organização das Nações Unidas. Mas certamente, pensar a democracia liberal em bases transnacionais, ou seja, para além das fronteiras territoriais nacionais, significa pensar o impacto que esse desdobramento tem sobre os conceitos centrais da democracia como legitimidade e representação. 
Nessa direção, a preocupação de David Held é a defasagem ou incongruência entre as decisões nacionais e suas conseqüências extranacionais e seus argumentos podem ser resumidos assim: a teoria liberal da democracia assume uma simetria e/ou congruência entre decision-makers políticos e os cidadãos eleitores. Um problema que tensiona essa simetria é que a comunidade nacional, através de seus representantes, toma decisões que acabam afetando tanto a seus cidadãos como aos cidadãos de outros países. A decisão de construir uma usina nuclear próxima da fronteira com outro país é uma decisão, por exemplo, que pode afetar a vida de milhares de pessoas além das fronteiras nacionais. $\mathrm{O}$ que quer responder Held é: como fazer para que as sociedades de outros países participem de decisões que, em princípio, parecem confinadas ao âmbito nacional? Como evitar a despolitização de decisões globais, que na verdade deveriam pressupor um demos transnacional capaz de decidir?

Held aponta que a sociedade civil internacional estaria deslocando o locus da soberania nacional para organizações internacionais, tais como a ONU, onde poderia estar representada a imaginária sociedade civil internacional. Assim, acabaria, de um lado, colocando em questão a autoridade do modelo westphaliano e, de outro, revertendo a perigosa despolitização gerada pela globalização. Held concebe, contudo, que em arranjos cosmopolitas e institucionais, a sociedade civil internacional conviveria com os Estados nacionais, porém também atribui à sociedade civil o importante papel da "fiscalização democrática" do mundo westphaliano dos Estados nacionais. Semelhante aos intelectuais wilsonianos da década de 20 do século passado, ao atribuírem à opinião pública o papel de fiscalização dos acordos e tratados entre Estados nacionais. De outro lado, num evidente exagero de seu pressuposto normativo, os movimentos sociais transnacionais seriam também importantes mediadores entre as instituições da governança cosmopolita e do correspondente demos cosmopolita. 
Somando-se às teorias celebratórias liberais, Held ainda destaca que a sociedade civil internacional agiria como um muro democrático contra a falta de prestação de contas e de transparência das instituições de governança. Diante desse cenário teórico, perguntamos: quais são os problemas dessa visão celebratória da sociedade civil internacional ou global?

A idéia de comunidade democrática, seja ela nacional ou cosmopolita, traz à tona, certamente, noções tais como a determinação de uma fonte de legitimidade, consentimento e constituency. Aqui aparece o primeiro problema não explicitado pelas teorias cosmopolitas de Held. Nas relações entre sociedade civil e democracia, os agentes da sociedade civil não podem escapar das seguintes perguntas críticas: quem são os constituintes da sociedade civil internacional? Como sua atuação pode ser considerada legítima? A quem remete sua representação? Como pode ser feita sua accountability?

Quando admitimos que a democracia, seja na sua forma processual, seja na forma de democracia substantiva, é um critério universal para legitimar a ação de um ator individual ou coletivo na arena pública, ao observarmos a atuação do ator público transnacional social, é com certa preocupação que percebemos que ainda os critérios da democracia (mesmo os minimalistas), não são aplicáveis à atuação dos agentes da sociedade civil internacional. Em outras palavras, mesmo quando estes atores se proclamam representantes de interesses societais nacionais ou transnacionais, não se conhecem casos nos quais uma assembléia de cidadãos nacionais ou globais proceda à eleição desses grupos ou movimentos para agir como delegados ou representantes, com mandato imperativo ou livre, em nome de uma sociedade local ou transnacional.

Para entender esse déficit democrático ainda não coberto pelos movimentos sociais ou ONGs com pretensões de representar interesses sociais globais, um primeiro aspecto a considerar é o seguinte: de que modo se articula o impera- 
tivo do pluralismo democrático e as diversidades de demandas levantadas por esses atores não-estatais (Urquidi, 2000). Em princípio, sabe-se que o que se pretendeu com a democracia moderna consolidada no locus do Estado-nação foi a integração da diversidade social por meio de mecanismos de representação que garantissem a participação e influência política da sociedade sobre a qual o Estado governaria. Propôs-se a composição de um governo para uma sociedade que compartilhasse a identidade e valores, em que as diferenças pudessem se apresentar e ser representadas. E que a diversidade pudesse ser mediada e coexistir num regime capaz de reconhecer o pluralismo como resultado natural da decomposição da comunidade e do desenvolvimento da individuação. Mesmo reconhecendo que não haveria uma homogeneidade social, a democracia representativa moderna não foi pensada para organizar politicamente a coexistência multicultural, nem a heterogeneidade tempo98 ral de formas produtivas, por exemplo, mas para construir um Estado-nacional, cuja condição de êxito seria a construção ou produção de uma nova homogeneidade ou cultura nacional sobre as diversidades das culturas locais. A pergunta que se segue a essas afirmações é quase óbvia: como é que a democracia transnacional cosmopolita poderia atingir essa promessa não cumprida da democracia liberal?

Paradoxalmente, os movimentos e organizações sociais e seus intelectuais celebratórios, ao tentarem se afastar da aparelhagem da democracia representativa correm o risco de perder uma ferramenta legitimada histórica e socialmente como procedimento de escolha da autoridade e de delegação de poder. Nesse contexto, adquire sentido a pergunta sobre os critérios de legitimidade da ação dos atores públicos da sociedade civil internacional. Na verdade, se temos que procurar uma fonte da "autoridade" e de legitimidade de uma sociedade civil de caráter internacional, aquela deveria ser procurada antes em critérios contingenciais ou 
em caráter não institucionalizado, que não correspondem aos padrões históricos da democracia formal ou representativa - reconhecendo-se que isto pode ser perda e não ganho em termos de realização democrática. A fonte de legitimidade da sociedade civil internacional deveria ser procurada no caráter quase dramático do debate no qual se articulam, isto é, nas respostas societais globais que apresentam, face os desequilíbrios sistêmicos gerados por fenômenos tais como a globalização dos problemas ecológicos e crise humanitária. Em outras palavras, a legitimidade parece ser atingida pela ação e não pelo procedimento que investe autoridade antes da ação; essa ação se concretiza de modo mais eficiente quando os agentes da sociedade civil internacional reagem àqueles desequilíbrios que afetam os aspectos de bem-estar, da economia, da saúde, da identidade cultural e da qualidade de vida dos cidadãos em todo o planeta. São estes os fenômenos para os quais o Estado-nacional e os procedimentos democráticos não tiveram resposta imediata, ao mesmo tempo em que a prática dos ativismos transnacionais e da institucionalização internacional não pôde esperar a teoria. O caráter mais flexível da resposta da assim chamada sociedade global e de seus mecanismos de atuação em rede acaba de fato imprimindo rapidez na resposta e faz parecer legítima a ação de grupos transnacionais sociais, desde que seus resultados sejam notoriamente reconhecidos como legítimos.

De outro lado, a globalização de processos como meio ambiente, direitos humanos, direitos raciais, de gênero, entre outros, sugere também o surgimento de novas categorias de direitos para os quais a unidade política territorial democrática tem uma resposta lenta, porque a velocidade na demanda supera amplamente a velocidade e eficácia com que é gerada a resposta nacional. Aliás, a lentidão democrática é muito própria das sociedades e dos sistemas políticos nacionais que operam sob seus pressupostos, já que 
os procedimentos e as regras são garantidores da democracia. Bobbio designa bem esse preço pago pelas democracias como "sobrecarga", ou seja, é custoso agir democraticamente, e a demora na solução das demandas se dá em função do excesso de demandas diante da lentidão e dificuldades do Estado democrático em responder a elas (Bobbio, 1988).

\section{Conclusão}

Deve-se atentar que o Estado nacional democrático não é a unidade errada para resolver e dar resposta às demandas geradas pelos problemas que decorrem da colocação de direitos que podem ser compreendidos como transnacionais. Trata-se sim de reconhecer que a natureza da demanda está em mudança, de local para transnacional, e nisso os representantes estatais são unidades políticas menos flexíveis na resposta, mas absolutamente necessários à democracia. Tanto que a forma não-institucionalizada de

100 atuação dos agentes da assim chamada sociedade civil internacional, diante da ausência de um mecanismo formal que recubra de legitimidade sua atuação, é um flanco aberto para críticas severas. O ponto crítico não é que esses grupos transnacionais societais estabeleçam novos critérios de legitimidade mas, precisamente, o ponto crítico é a ausência de tais critérios.

Um outro aspecto para o qual se deve atentar é que o déficit de legitimidade entre diferentes agências no interior da sociedade civil internacional é mais acentuado em algumas do que em outras, quando consideramos sua relação com os Estados. Parece claro que a procura de meios legítimos é uma preocupação menor entre as ONGs do que entre os movimentos sociais transnacionais. Isso é um sinal de que o Estado-nacional democrático ainda é fundamental, porque longe de ser algo circunstancial ou contingencial, a legitimidade dos agentes da sociedade civil internacional continua intimamente conectada ao critério da soberania 
e ao modelo de autoridade do governo político moderno, isso por várias razões:

Em primeiro lugar, porque o que chamamos de 'sociedade civil internacional' não gerou regras democráticas próprias ainda. Quando sua ação se alimenta de regras preexistentes, recorre aos critérios normativos nacionais ou internacionais existentes; em segundo lugar, porque na sua visão otimista, os teóricos da democracia cosmopolita ignoram que algumas das demandas da sociedade civil às instituições (nacionais ou internacionais) são mediadas por atores estatais; por último, porque nem toda atuação dos agentes da sociedade civil internacional se dá em oposição à defesa e interesse dos Estados nacionais democráticos. Em muitos casos as ONGs aceitam reforçar as capacidades do atores governamentais com instrumentos existentes abaixo do nível estatal. Com orientações mais pragmáticas do que ideológicas, alguns movimentos sociais buscam reformas institucionais que ampliem o sistema de participação de seus membros no processo de tomada de decisão. O que se constata é que, antes de assumir uma situação antagônica em relação ao Estado, a demanda por maior participação ou autonomia de ação das ONGs força uma postura de oposição e contestação dos formatos tradicionais de representação de interesse, que abrange inclusive partidos políticos e organização sindical, além do Estado

Nesse contexto, reconhecemos que permanece um certo grau de ambigüidade na ação de alguns agentes da sociedade civil internacional, já que o fato de eles não serem governamentais não significa que não sejam políticos, dado que sua atividade é carregada de conseqüências sobre a comunidade política existente. O problema é que poucas ONGs e, às vezes, alguns movimentos sociais, estão dispostos a reconhecer a responsabilidade política e ética que deriva da participação ou da busca de interferência em uma comunidade política (o que necessariamente envolve 
defesa das fontes e critérios da accountability de um grupo). Há casos de movimentos sociais que têm aceitado as implicações da natureza política de sua atividade, e nesses casos, a sociedade civil internacional pode ser considerada um possível site de um progressivo mundo político internacional e sua base seria dada, não por uma sociedade civil em abstrato, mas por movimentos sociais que têm mais fontes de legitimidade do que outros que falham ao identificar suas fontes ou não se interessam pelas fontes tradicionais (Colás, 2002, 157-60).

Cabe uma crítica final às teorias da governança global e da democracia cosmopolita. Consideramos que a globalização, ao contrário do que pensam intelectuais como Richard Falk, não cria necessariamente vínculos solidários entre movimentos sociais. Estes tendem muito mais a dissolver-se no ambiente globalizado do que se enlaçarem. Em lugar de conseguir uma universalização efetiva, a globalização vem 102 desencadeando particularismos, endurecidos nacionalismos contidos, acentuando o fundamentalismo de valores num movimento de "desfiliação universal e de filiação particularista” (Zaki, 1994, p. 67). Além disso, é possível fazer algumas objeções teóricas à idéia de democracia cosmopolita, face ao seu otimismo com o projeto ético da sociedade civil internacional.

Em primeiro lugar, ao questionar a legitimidade do Estado como o principal depositário da autoridade, os teóricos da democracia cosmopolita subestimam "a necessidade da democracia estar enraizada em comunidades de fato", ou seja, "comunidades que realmente governam, que determinam o futuro e continuam sendo o locus dos direitos" (Colás, 2002, p.157).

Em segundo lugar, colocando de lado o formato de autoridade do Estado-nação (como se não fosse mais eficaz), tais teorias arriscam a reificação da sociedade civil (seja local, regional ou global) como a principal esfera da 
deliberação. A premissa de Held de que, sob condições de globalização, o conceito de poder político legítimo tem que ser separado da tradicional associação com os Estados, leva a uma conclusão apressada de que os limites nacionais não são mais satisfatórios para responder às demandas transnacionais e isso corresponderia ao surgimento de uma esfera pública global genuinamente democrática. Entretanto, ainda que os Estados já fossem ineficazes, nada garantiria uma correspondente eficácia de uma esfera não estatal de deliberação democrática, ou sequer a possibilidade de sua constituição. Contrariamente, o que verificamos é que uma firme garantia contra os perigos da exploração e alienação globalista repousa no fortalecimento do Estado democrático nacional. Claro que, com isso, não resta qualquer mérito à ambição cosmopolita de transcender a divisão artificial da humanidade em Estados nacionais, pois cabe lembrar que historicamente a sociedade civil tem emergido e se desenvolvido sob os eixos de um legítimo e extensivo Estado democrático (Colás, 2002).

Além disso, não discordamos do ideal de paz e solidariedade e sim da efetividade de um projeto que subestima a capacidade de resiliência do Estado nas relações internacionais. Como afirma Gilpin (2001), melhor seria se os ricos pretendessem distribuir sua riqueza aos pobres, mas assim como se dá nas relações econômicas domésticas, as relações internacionais têm se mostrado semelhantes quanto ao fato de que os Estados poderosos não são generosos, não se tornaram solidários nem estão pretendendo abrir mão de seu poder e soberania. A conseqüência disso é que eles têm se capacitado para orquestrar relações transnacionais de modo eficiente, além de estarem aproveitando muito bem os novos recursos de poder propiciados pela globalização, ao mesmo tempo em que a impulsionam. Nesse contexto, porém, novos mecanismos de representação não se mostraram ainda seguramente democráticos, mas muitas ações 
transnacionais têm influenciado o poder estatal ${ }^{10}$. Assim, tanto para o mal na luta por poder, mas também para o bem da democracia, o Estado permanece. O cosmopolitismo continua a ser um valor, e no entanto o problema parece radicar na subestimação do lugar estratégico da soberania estatal face aos objetivos da democracia cosmopolita, inclusive porque o reconhecimento do poder dos Estados interessa também à democracia.

Em síntese, pensar a democracia em bases transnacionais não parece só questionar a fonte da legitimidade estatal para referendar democraticamente arranjos normativos e institucionais pensados além da fronteiras, mas também a própria legitimidade dos agentes que questionam sua legitimidade, ou seja, os movimentos sociais e atores não estatais tomados como os atores mais genuínos do projeto ético de sociedade civil.

104 Rafael Duarte Villa

é professor do Departamento de Ciência Política da Universidade de São Paulo

\section{Ana Paula Baltasar Tostes}

é professora-visitante no Departamento de Ciência Política da Universidade de São Paulo

\footnotetext{
10. Podemos destacar o papel importante dos atores não estatais na aprovação do Estatuto de Roma, que cria o Tribunal Penal Internacional, ou dos ativismos transnacionais em casos de desenvolvimento sustentável, direitos humanos, violência contra as mulheres e índios, por exemplo, relatados por autores como Maria Guadalupe Moog Rodrigues (2004) e Keck \& Sikkink (1998).
} 


\section{Referências bibliográficas}

BEITZ, Charles R. "Sovereignty and Morality in International Affairs". In: D. Held (Ed.), Political theory today. Stanford: Stanford University Press. 1991. BULL, H. A sociedade anárquica. São Paulo: Imprensa Oficial de São Paulo. 2002.

BOBBI0, Norberto. "Democracia y sistema internacional". In: BOBBIO, N. Norberto Bobbio: El filósofo y la política. México: Fondo de Cultura Económica. 1996.

. Liberalismo e democracia. São Paulo: Brasiliense. 1988.

. O futuro da democracia. São Paulo: Paz e Terra. 1986.

CARDIN, José Henrique. "O conceito de paz democrática, entre o idealismo e o realismo”. Caderno Sábado. In: Folha da Tarde, 05 de fevereiro de 1999.

CARR, Edward. Vinte anos de crise 1919-1939. Brasília: Editora da Universidade de Brasília. 1981.

COLÀS, Alejandro. International civil society. Social movements in world politics. Cambridge: Polity. 2002.

CZEMPIEL, Ernst-Otto. Governança sem governo. Brasília/São Paulo: Editora da UNB/Imprensa Oficial. 2000.

DAHL, Robert A. "A democratic dilemma: System effectiveness versus citizen participation”. In: Political Science Quartely, v. 109, n. 1, p. 23-34. 1994.

DOYLE, Michael. "Liberty and democracy: Realists and liberals contest a legacy”. In: COX, Michael; IKENBERRY, G. J.; INOGUCHI, Takashi (Eds.). American democracy promotion: Impulses, strategies, and impacts. Oxford: Oxford Universtiy Press Inc., 2000.

DOMINGUEZ, Jorge. "Security, peace, and democracy in Latin America and the Caribbean: Challenges for the Post-Cold War Era”. In: DOMINGUEZ, Jorge (Ed.) International security and democracy: Latin America and the Caribbean in the post-cold war. Pittsburgh: University of Pittsburgh Press. 1998.

DUPAS, Gilberto. A Europa em ano de desafio. In: Panorama da conjuntura internacional, ano 2, n. 5, maio/junho 2000.

FALK, Richard. "The world order between inter-state system law and the law of humanity: The role of civil society institutions". In: D. Archibugi \& D. Held (Eds.) Cosmopolitan democracy: An agenda for a new world order. Cambridge: Polity. 1995.

FUKUYAMA, Francis. "The end of history?”. In: The national interest. Summer 1989.

GILPIN, Robert. Global politics economy: Understanding the international economic order. Princepton: Princepton University Press. 2001.

HELD, David. "A democracia, o Estado-Nação e o sistema global”. Lua Nova, n. 23, março 1991, p. 145-194. 
Democracy and the global order: From the modern state to cosmopolitan governance. Califórnia: Stanford California Press. 1995.

. Democracy and the global order. Cambridge: Polity Press. 1991.

The transformation of political community: Rethinking democracy in the context of the globalization. In: ARCHIBUGI, D.; HELD, D.; KPHLER, M. (Eds.). Re-imagining the political community: Studies in cosmopolitan democracy. Califórnia: Stanford University Press. 1998.

HIRST, Paul e THOMPSON. Globalização em questão. Petrópolis: Vozes, 1998. HUTH, Paul K. \& ALLEE, Todd L. The democratic peace and territorial conflict in the twentieth century. Cambridge: Cambridge University Press. 2002.

JOSEPH, A. Camilleri; FALK, Jim. The end of sovereignty? The politics of a shrinking and fragmenting world. Aldershot: Edward Elgar Publishing Limited.1992.

KANT, Immanuel. A paz perpétua e outros opúsculos. Lisboa: Edições 70. s/d.

KECK, Margaret E., SIKKINK, Kathryn. Activists beyond borders. Advocacy transnational networks in international politics. Londres: Cornell University Press. 1998.

KENNEDY, Paul. Preparando para o século XXI. Rio de Janeiro: Campus. 1993.

KEOHANE, Robert 0.; NYE, Joseph S. Jr. "Realism and complex interdependence". In: WILLIAMS, Marc (Ed.). International relations in the twentieth century: A reader. Londres: The Macmillan Press Ltd., 1989.

KEOHANE, Robert 0. After hegemony: Cooperation and discord in the world political economy. Princeton, NJ: Princeton University Press. 1984.

Instituciones internacionales y poder estatal. (Trad. Cristina

Piña). Buenos Aires: Grupo Editos latinoamericano, 1989.

KYMLICKA, Will. "Citizen in an era of globalization: Commentary on Held”. In: ARCHIBUGI, D.; HELD, D.; KPHLER, M. (Eds.). Re-imagining the political community: Studies in cosmopolitan democracy. Califórnia: Stanford University Press. 1998.

NINCIC, Miroslav. Democracy and foreign policy: The fallacy of political realism. Nova York: Columbia University Press. 1992.

PUTNAM, Robert D. "Diplomacy and domestic politics: The logic of two level games”. In: International Organization, 42(3): 427-460. 1993.

ROBERTSON, Roland. "Mapeamento da condição global: Globalização como conceito central”. In: Featherstone, M. (Org.). Cultura global. Nacionalismo, globalização e modernidade. (Trad. de Attílio Brunetta). Petrópolis: Vozes. 1994.

RODRIGUES, Maria Guadalupe Moog. Global environmentalism and local politics.

Transnational advocacy networks in Brazil, Ecuador and India. Albany: State University of New York Press. 2004. 
ROSENAU, James N. "A cidadania em uma ordem mundial em mutação". In: ROSENAU, James e CZEMPIEL, Ernst-Otto (Orgs.) Governança sem governo: Ordem e transformação na política mundial. São Paulo/Brasília: Imprensa Oficial/Unb. 2000.

SINGER, Paul. "Globalização positiva e globalização negativa: a diferença é o Estado”. Novos Estudos, CEBRAP, n. 48, julho, 1997.

SMITH, Anthony D. "Criação do Estado e construção da Nação". In: Hall, J. A. (Org.). Os Estados na história. Rio de Janeiro: Imago Editora. 1992. . (1986). "Para uma cultura global?". In: Featherstone, M. Cultura global. (Trad. de Attílio Brunetta). Petrópolis: Vozes, p. 186-205. 1994. STRANGE, Susan. "As supranacionais e o Estado". In: Hall, J. A. (Org.). Os Estados na história. (Trad. de Paulo Vaz et al.). Rio de Janeiro: Imago Editora, p. 422-446. 1992.

TOCQUEVILLE, Alexis de. A democracia na América. Belo Horizonte: Itatiaia, 1987.

TOSTES, Ana Paula. "Identidades transnacionais e o Estado: Viço e teimosia?”. Lua Nova, n. 63, 2004, p. 39-63.

URQUIDI, Vivian. Movimento cocalero na Bolívia: Heterogeneidade temporal e diversidade cultural. (2000) Tese de Doutorado, Universidade de São Paulo. 2000.

VILLA, Rafael D. "Formas de influência na política internacional". Revista de Sociologia e Política, n. 12, jun. 1999, p. 21-33.

WALTZ, Kennetz. Teoria das relaçôes internacionais. Lisboa: Gradiva. 2000.

ZAKARIA, Fareed. The future of freedom: Liberal democracy at home and abroad. Nova York: W.W. Norton \& Company. 2003.

ZAKI, Ladi. Un monde privé de sens. Paris: Fayard. 1994. 


\section{DEMOCRACIA COSMOPOLITA VERSUS POLÍTICA INTERNACIONAL}

RAFAEL DUARTE VILLA E ANA PAULA BALTASAR TOSTES

O objetivo deste artigo é mostrar os pontos de tensão, as hipóteses fortes e as teses otimistas e/ou pessimistas que perpassam os vínculos entre o modelo westphaliano internacional de soberania, a democratização do sistema internacional e a sociedade civil internacional. $\mathrm{O}$ artigo examina as seguintes questões: na primeira, recupera-se a discussão clássica sobre democracia e relações internacionais; na segunda, trata-se das relações entre globalização e democracia; na terceira, as tensões entre democracia (transnacional) e as novas noções de representação; finalmente, mostram-se os pontos críticos da visão celebratória da sociedade civil internacional pregada pelas teorias cosmopolitas da democracia.

Palavras-chave: Democracia Cosmopolita; Relações Internacionais; Representação; Estado-Nacional

\section{COSMOPOLITAN DEMOCRACY VERSUS INTERNATIONAL} POLITICS

This paper intends to show the points of tension, strong hypothesis, and optimistic and/or pessimistic thesis which go through the connections between the Westphalian international model of sovereignty, the democratization of the international system, and the international civil society. This article examines the following issues. First, we review 
the classical debate about democratization and international relations. Second, we address the relations between globalization and democracy. The third part is dedicated to the tensions between transnational democracy and new notions of representation. Finally, we pin-point the critical aspects of the celebratory vision of the international civil society, as advocated by the cosmopolitan theories of democracy.

Keywords: Cosmopolitan Democracy; International Relations; Representation; Nation-State. 